University of Nebraska - Lincoln

DigitalCommons@University of Nebraska - Lincoln

\title{
Transient expression of the ectodomain of matrix protein 2 (M2e) of avian influenza A virus in plants
}

\author{
Lev G. Nemchinov \\ United States Department of Agriculture \\ Angela Natilla \\ United States Department of Agriculture
}

Follow this and additional works at: https://digitalcommons.unl.edu/usdaarsfacpub

Part of the Agricultural Science Commons

Nemchinov, Lev G. and Natilla, Angela, "Transient expression of the ectodomain of matrix protein 2 (M2e) of avian influenza A virus in plants" (2007). Publications from USDA-ARS / UNL Faculty. 369.

https://digitalcommons.unl.edu/usdaarsfacpub/369

This Article is brought to you for free and open access by the U.S. Department of Agriculture: Agricultural Research Service, Lincoln, Nebraska at DigitalCommons@University of Nebraska - Lincoln. It has been accepted for inclusion in Publications from USDA-ARS / UNL Faculty by an authorized administrator of DigitalCommons@University of Nebraska - Lincoln. 


\title{
Transient expression of the ectodomain of matrix protein 2 (M2e) of avian influenza $A$ virus in plants
}

\author{
Lev G. Nemchinov *, Angela Natilla \\ Molecular Plant Pathology Laboratory, Plant Sciences Institute, United States Department of Agriculture, Agricultural Research Service, \\ 10300 Baltimore Avenue, Beltsville, MD 20705, USA
}

Received 29 March 2007, and in revised form 4 May 2007

Available online 7 June 2007

\begin{abstract}
We have previously reported an expression system based on the capsid protein gene (CP) of cucumber mosaic virus (CMV) placed under transcriptional control of a potato virus X (PVX)-based vector. PVX-expressed CMV CP formed virus-like particles, which served as carriers for heterologous antigens of the Newcastle disease virus (NDV).

In this work, we applied our expression tool toward the development of plant-derived vaccine candidate against avian influenza A virus. Twenty-three amino acid-long extracellular domain of the viral M2 protein (M2e) was engineered into the internal motif 5 of CMV CP and the recombinant gene then was transiently expressed in plants through a PVX vector. Chimeric CMV capsids reacted with specific antibodies produced to synthetic M2e epitope of the H5N1 strain of the virus. In addition, CMV CP-M2e protein was expressed to high levels in Escherichia coli bacterial cells and was recognized by antibodies to both CMV and M2e. This initial study demonstrates the feasibility of using plant virus-based vectors for expression of antigenic epitopes of H5N1 avian influenza in plants.

Published by Elsevier Inc.
\end{abstract}

Keywords: Plant-derived vaccines; Avian influenza virus; M2 extracellular domain

Influenza type A virus is classified into several subtypes which vary in two of their transmembrane proteins, hemagglutinin (HA) ${ }^{1}$ and neuraminidase (NA) and possess similar nucleoprotein and matrix protein [1]. A constant antigenic reassortment in surface-located HA and NA, which are, respectively, responsible for binding of the virus to its cellular receptor and promoting release of the mature virus from infected cells [2], makes vaccine development a complicated process. There are 16 known HA subtypes and nine known NA subtypes of influenza A viruses and many different combinations are possible. Three subtypes,

\footnotetext{
* Corresponding author. Fax: +1 0113015045449.

E-mail address: Lev.Nemchinov@ba.ars.usda.gov (L.G. Nemchinov).

${ }^{1}$ Abbreviations used: CP, capsid protein gene; CMV, cucumber mosaic virus; PVX, potato virus X; NDV, Newcastle disease virus; HA, hemagglutinin; NA, neuraminidase; M2, matrix protein 2; NBT, nitroblue tetrazolium chloride; BCIP, bromo-chloro-indolyl phosphate; VLP, virus-like particles; HBc, hepatitis B virus core; KLH, keyhole limpet hemocyanin; CSFV, classical swine fever virus.
}

(H1N1, H1N2, and H3N2), commonly circulate among humans and all known subtypes of influenza A viruses can be found in birds [3]. Influenza A subtype H5N1 virus, known as avian influenza or bird flu, is endemic mainly in birds and does not usually infect people. However, because of its high virulence, H5N1 may be transmitted from infected birds to humans and cause fatal disease. The cumulative number of laboratory-confirmed human cases of avian influenza H5N1 reported to WHO by September 25, 2006 is 16 [4]. Currently, vaccines against influenza viruses are produced each year after thorough global surveillance, analyzing and prediction of the main circulating strains. Vaccines normally include HA as a main component of the inactivated virus and antigenic similarity between a circulating viral strain and the vaccine strain is a decisive factor of vaccine's efficacy [2]. The matrix protein 2 (M2) is a third and the smallest transmembrane integral protein of the virus which, unlike HA and NA, is highly conserved among influenza A strains [5]. M2 forms ion 
channels composed of tetramers of M2 and is essential for efficient virus replication. It has been demonstrated elsewhere that an extracellular part of the M2 protein (M2e) consisting of 23 amino acids may serve as a vaccine target and elicit production of neutralizing antibodies against infection [6-8]. Several M2e conjugates, including M2e fusion with an immunodominant epitope of hepatitis B virus core protein provided a high degree of protection against a lethal virus challenge in mice [7,8]. Judging from these findings, recombinant M2e-based vaccine candidates represent a promising alternative to the existing vaccines, which are not adapted to continuous virus variability.

Our research is focused on the use of plants as biofactories for the overproduction of vaccines and therapeutic proteins. Plants represent inexpensive, environmentally friendly sources of raw materials and can be grown anywhere locally without expensive fermentation equipment. We have previously reported an expression system based on capsid protein gene (CP) of cucumber mosaic virus Ixora strain (CMV-Ix) placed under transcriptional control of potato virus X (PVX)-based vector. PVX-expressed CMV CP formed virus-like particles which served as carriers for heterologous antigens of Newcastle disease virus (NDV) [9]. In this work, we applied our expression tool toward the development of a plant-derived, M2e-based vaccine candidate against avian influenza virus. Plantmanufactured CMV capsids displaying M2e epitope reacted to specific antibodies raised against synthetic $\mathrm{M} 2 \mathrm{e}$ peptide. Immunoreactive CMV CP-M2e protein was also expressed to high levels in Escherichia coli cells using Invitrogen's pET151 expression vector. To the best of our knowledge, this is the first report of the production of a potential neutralizing epitope of avian influenza virus in plants.

\section{Materials and methods}

\section{Construction of recombinant plant virus}

Consensus M2e epitope SLLTEVETPTRNEWECRCSDSSD, obtained by multiple alignment of different reported $\mathrm{H} 5 \mathrm{~N} 1$ isolates of the virus was incorporated into motif 5 of CMV Ixora CP by fusion PCR as described in Natilla et al. [9]. Three PCR primers were made to perform the reaction:

1. Complementary primer to amplify the $5^{\prime}$-terminus of CMV-Ix CP upstream of the insertion together with the $5^{\prime}$ half of the M2e epitope (upper case M2e, small case CMV CP): 5'-TTCTAGTAGGAGTTTCCACTT CAGTAAGAAGTGActcgagcgcatcgtcttttg- $3^{\prime}$. This primer was used with previously reported homologous CMV CP primer LN10 [9].

2. Homologous primer to amplify the 3 '-terminus of CMVIx CP downstream from the insertion together with the $3^{\prime}$ half of M2e epitope (upper case M2e, small case CMV CP): 5'-ATGAATGGGAATGTAGATGTTCTG
ATTCTTCTGATacggatgagctggtactccatg- $3^{\prime}$. This primer was used with previously reported complimentary CMV CP primer LN2 [9].

3. Complementary overlapping primer to anneal two PCR products in one reaction and produce the complete $\mathrm{M} 2 \mathrm{e}$ epitope inserted into CMV CP: 5'-CTACATTCCC ATTCATTTCTAGTAGGAGTTTC-3'.

Amplified PCR product comprising the M2e epitope incorporated into motif 5 of CMV CP (Fig. 1a), was cloned first into pCR TOPO II vector (Invitrogen) following by subcloning into PVX-based vector pP2C2S (obtained by Molecular Plant Pathology Laboratory from D. Baulcombe, Sainsbury Laboratories, Norwich, England) as described [9].

\section{Transcript preparation and inoculation of plants}

Plasmids were linearized using restriction enzyme SpeI, and capped T7-RNA polymerase transcripts were generated from cDNA clones using Ambion's T7 mMessage Machine kit (Ambion, Austin, TX). The transcripts were mechanically inoculated onto fully expanded leaves of Nicotiana benthamiana.

\section{Whole leaf squash blots}

The procedure has been performed as described in Hendy et al. [10] with minor modifications. Briefly, individual leaves from infected plants were immersed in liquid nitrogen for 1-2 s. Leave were placed on a nitrocellulose membrane and allowed to return to room temperature for $\sim 5 \mathrm{~min}$. Pressure was evenly applied over the leaf surface for $30 \mathrm{~min}$. Membranes were dried at room temperature for $10 \mathrm{~min}$ and then incubated in $5 \% \mathrm{w} / \mathrm{v}$ non-fat milk powder in $1 \times$ PBS- $-0.05 \%$ Tween 20 for $1 \mathrm{~h}$ at room temperature (RT) to prevent non-specific binding. The membranes were then incubated with rabbit polyclonal antibodies raised against M2e epitope diluted to 1:1000 in blocking solution for $2 \mathrm{~h}$ at RT followed by incubation with goat anti-rabbit IgG-alkaline phosphatase conjugate (Sigma) for $2 \mathrm{~h}$ at RT. Blots were washed three times with $1 \times$ PBS- $-0.05 \%$ Tween 20 and developed with nitroblue tetrazolium chloride (NBT) and bromo-chloro-indolyl phosphate (BCIP, Kirkegaard and Perry Laboratories, Inc., Gaithersburg, MD).

\section{Reverse transcription-polymerase chain reaction ( $R T-P C R)$}

Total nucleic acids were extracted using TRI Reagent (Molecular Research Center, Inc., Cincinnati, OH) from non-inoculated symptomatic leaves 5-7 days post-inoculation (dpi). RT and PCR were performed in a single reaction mixture utilizing an RT-PCR Titan One Tube kit as described by the manufacturer (Roche Molecular Biochemicals, Chicago, IL) and the CMV CP-specific primer pair 
a

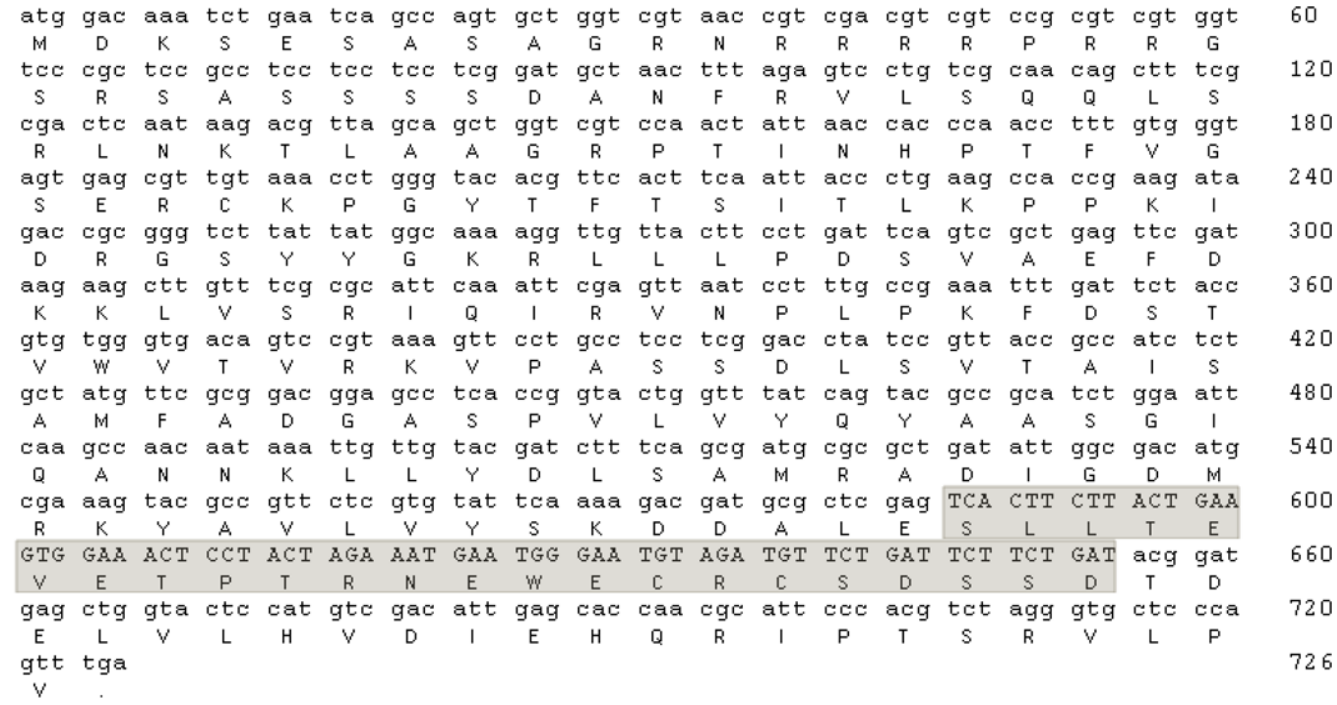

b

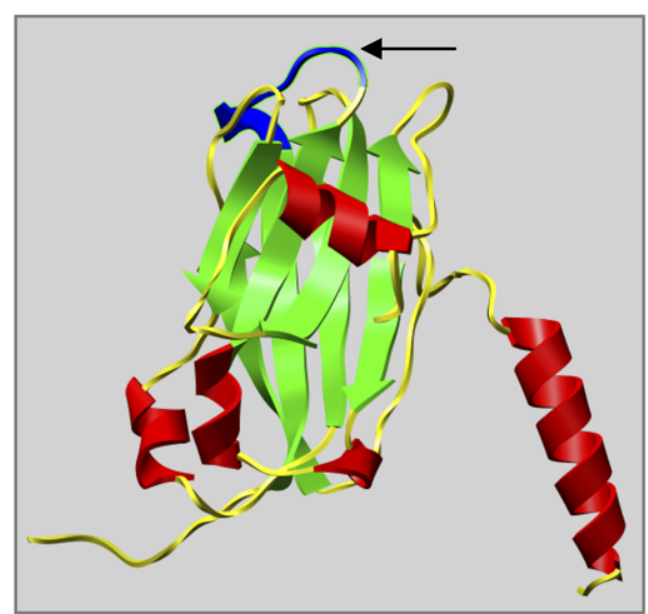

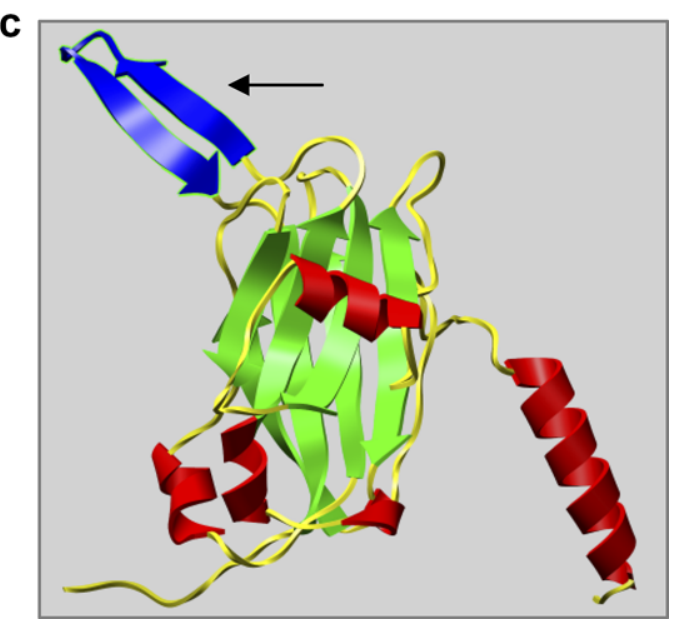

Fig. 1. (a) Nucleotide $\left(5^{\prime}-3^{\prime}\right)$ and amino acid sequence of the chimeric CMV-Ix CP gene with incorporated M2e epitope of avian influenza virus (highlighted). ( $b$ and c) Predicted secondary structures of the wild type CMV CP subunit and hybrid CMV CP with M2e epitope, respectively. Arrows indicate $\beta \mathrm{H}-\beta \mathrm{I}$ loop (motif 5).

LN2/LN10. The PCR fragments were fractionated by electrophoresis on a $0.8 \%$ agarose gel.

\section{Analysis of protein expression by Western blot}

Fifty to $100 \mathrm{mg}$ of leaf tissues were homogenized in Eppendorf tubes in 1× PBS buffer containing 1:100 dilution of protease inhibitors cocktail (Sigma). After centrifugation for $10 \mathrm{~min}$ at $13,200 \mathrm{rpm}$ (relative centrifugal force of 16,110g, Eppendorf centrifuge model 5415D), the supernatant was mixed with $2 \times$ Laemmli loading buffer and electrophoresed on pre-cast Novex 10-20\% Tris-Glycine gels (Invitrogen), following by blotting onto a nitrocellulose membrane (Invitrogen). Membranes were probed with polyclonal antibodies to CMV (ATCC) or polyclonal antibodies produced against synthetic M2e peptide. A synthetic M2e peptide of the respective amino acid sequence SLLTEVETPTRNEWECRCSDSSD and rabbit polyclonal antibodies were produced by Pacific Immunology Corp.,
Ramona, CA, according to the company protocols. Specificity of antibody and reactivity of the synthetic peptide were tested in separate experiments by Western blot assays (not shown). Reactions were developed with NBT/BCIP (Kirkegaard and Perry Laboratories, Inc., Gaithersburg, MD).

\section{Direct M2-ELISA protocol for protein quantification}

Fifty milligrams of leaf tissues were homogenized in Eppendorf tubes in $400 \mu \mathrm{l}$ of $1 \times$ PBS buffer containing 1:100 dilution of protease inhibitors cocktail (Sigma). After centrifugation for $10 \mathrm{~min}$ at $13,200 \mathrm{rpm}$ (relative centrifugal force of $16,110 \mathrm{~g}$, centrifuge model $5415 \mathrm{D}$ Eppendorf), ELISA plates were coated with $100 \mu \mathrm{l}$ of the resulting supernatant and incubated at $4{ }^{\circ} \mathrm{C}$ overnight. Different known concentrations of synthetic M2e peptide, diluted in supernatant obtained in a similar way from non-infected $N$. benthamiana plants, were used 
as positive controls and a supernatant from non-infected plant without addition of M2e peptide served as a negative control. After incubation plates were washed twice by filling the wells with $200 \mu \mathrm{l}$ of $1 \times$ PBS and shaking for $3 \mathrm{~min}$ in Boekel Jitterbug Microplate Incubator Shaker (Boekel Scientific). Antigen-coated wells were blocked by adding $200 \mu \mathrm{l}$ per well of blocking buffer, $5 \%$ non-fat dry milk in $1 \times$ PBS. The plate was incubated for $2 \mathrm{~h}$ at room temperature, washed twice with $1 \times$ PBS and loaded with 1:1000 dilution of rabbit polyclonal antibodies to the M2e peptide (Pacific Immunology) in blocking buffer. Plates then were incubated $2 \mathrm{~h}$ at room temperature, washed 5 times with $1 \times$ PBS and loaded with 1:5000 dilution of polyclonal goat anti-rabbit antibodies conjugated to alkaline phosphatase (Sigma). Following 5 times thorough washing, $100 \mu \mathrm{l}$ of the substrate solution ( $p$-nitrophenylphosphate, KPL) were dispensed into each well. After sufficient color development the absorbance values were read with Bio-Rad 680 microplate reader.

\section{Protein expression in E. coli}

CMV CP-M2e fusion gene as well as wild type (WT) CMV CP were re-amplified using pCR TOPO II/CMV CP-M2e and pCR TOPO II/CMV CP-WT plasmids as templates and cloned into pET151 Directional TOPO vector following manufacturer's directions (Invitrogen). Proteins were expressed using BL21 Star (DE3) One Shot Chemically Competent Cells under recommended conditions (Invitrogen). IPTG was added to a final concentration of $1 \mathrm{mM}$ and induced cultures incubated for $4-6 \mathrm{~h}$ at $37^{\circ} \mathrm{C}$. Samples were then pelleted by centrifugation, resuspended in $500 \mu \mathrm{l}$ of lysis buffer $(50 \mathrm{mM}$ potassium phosphate, $\mathrm{pH} 7.8,0.4 \mathrm{M} \mathrm{NaCl}, 0.1 \mathrm{M} \mathrm{KCl}, 10 \%$ glycerol, $0.5 \%$ Triton $\mathrm{X}-100$, and $10 \mathrm{mM}$ imidazole) and treated as advised by manufacturer to separate soluble protein from insoluble (Invitrogen). Insoluble protein was further purified under denaturing conditions in $1 \mathrm{ml}$ of $8 \mathrm{M}$ urea, $0.1 \mathrm{M} \mathrm{NaH} \mathrm{NO}_{4}, 0.01 \mathrm{M}$ Tris- $\mathrm{HCl}, \mathrm{pH}$ 8.0 , and $600 \mu \mathrm{l}$ of cleared lysate was loaded onto preequilibrated Ni-NTA spin columns designed for purification of $6 \times$ His-tagged proteins from small-scale bacterial expression cultures (Ni-NTA Spin Kit, Qiagen). Spin columns were washed twice and protein eluted as described by the manufacturer (Qiagen). Eluates were analyzed by PAGE following by staining with SimplyBlue ${ }^{\mathrm{TM}}$ SafeStain reagent (Invitrogen) or Western blot and probing with specific antibodies.

\section{Sequencing}

All recombinant constructs and RT-PCR products amplified from infected plants were sequenced on an ABI-PRIZM 373A Genetic Analyzer at the DNA Sequencing Facility, Center for Biosystems Research, College Park, MD. Sequence data were analyzed using Lasergene software by DNASTAR (Madison, WI).

\section{Results}

\section{Design of recombinant $C M V C P-M 2$ constructs}

The M2e epitope was engineered into the internal $\beta \mathrm{H}-\beta \mathrm{I}$ loop [11] of the CMV CP Ixora strain between glutamic acid (E-195) and threonine (T-196), similar to the previously described epitopes of Newcastle disease virus [9]. As predicted by automated proteomic server ExPASy at http:// swissmodel.expasy.org/ and reconstructed by molecular graphics program (UCSF Chimera package, University of California, San Francisco), addition of the M2e epitope would further extend the $\beta \mathrm{H}-\beta \mathrm{I}$ loop exposed on the surface, enhancing its antigenic potential (Fig. $1 \mathrm{~b}$ and c).

\section{Symptoms and stability of the recombinant virus in plants}

The recombinant PVX/CMV CP-M2e virus vector was infectious and caused typical PVX symptoms of vein clearing and chlorotic mosaic on leaves of inoculated $N$. benthamiana plants 5-7 days post inoculation (not shown). The engineered virus remained stable and produced chimeric CMV CP with H5N1 M2e epitope for two weeks post inoculation after which time the virus gradually reverted to WT. The hybrid virus remained stable for the same period of time after the second passage from transcript-inoculated plants. The second passage, however, had to be carried out from non-symptomatic transcript-inoculated plants 2-3 days post inoculation to preserve the predominantly recombinant form of the virus in the inoculum. Expression of CMV CP-M2e was monitored by Western blotting.

\section{Squash blots}

Whole leaf squash blots developed with antibodies specific to the M2e epitope showed that PVX-expressed recombinant CMV CP-M2e protein is uniformly distributed and accumulated throughout the entire leaf tissue of the infected plants (Fig. 2a and b).

\section{$R T-P C R$}

Total RNA samples extracted from virus-inoculated plants were used for RT-PCRs with primers specific to $\mathrm{CMV} \mathrm{CP}$ and/or to the $\mathrm{pP} 2 \mathrm{C} 2 \mathrm{~S}$ (PVX) sequence regions surrounding the multiple cloning site of the virus-vector. Gene-specific RT-PCR products indicated the presence of recombinant CMV CP-M2e mRNA (Fig. 2c). RT-PCR products were purified with MinElute Reaction Cleanup Kit (Qiagen) and sequenced. The sequence was identical to the original CMV CP-M2e construct obtained by fusion PCR.

\section{Expression of recombinant protein in plants}

When clarified plant extracts were electrophoresed through $10-20 \%$ Tris-Glycine gels, transferred to 

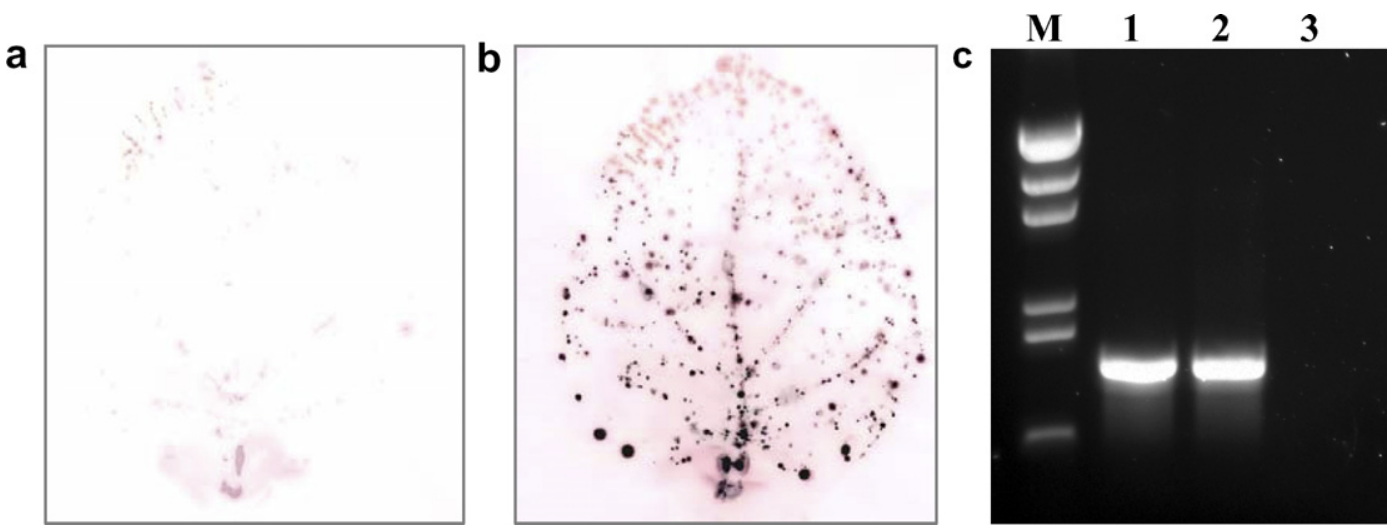

Fig. 2. (a and b) Whole leaf squash blots probed with antibodies to the M2e epitope. (a) Plant infected with recombinant PVX containing a wild type (WT) gene of CMV-Ix coat protein (CP); (b) plant infected with PVX containing the CMV CP-M2e fusion. (c) RT-PCR products amplified from plants infected with recombinant PVX/CMV CP- M2e virus using CMV CP-specific primers LN2/LN10. M, Lambda DNA EcoRI/HindIII marker (Promega): 2, 1.5, 1.3, 0.9, 0.8, and $0.5 \mathrm{~kb}$. Lanes 1 and 2, RT-PCRs from two different plants infected with PVX/CMVCP-M2e virus; lane 3, RT-PCR from plant infected with WT PVX.

nitrocellulose membrane and probed with either CMVspecific antibodies or antibodies specific to synthetic M2e peptide, the expected size bands corresponding to the CMV CP carrier fused to the M2e epitope were clearly observed on the membranes (Fig. 3a and b) thus demonstrating immunoreactivity of the recombinant fusion protein. Recognition by M2e-specific antibodies insured that the antigen inserted in $\beta \mathrm{H}-\beta \mathrm{I}$ loop of CMV CP is accessible and would likely elicit specific immune response.

Using colorimetric M2e-ELISA assay, the amount of recombinant CMV-M2e protein in an infected plant extract was measured by comparison of the OD values at $405 \mathrm{~nm}$ with known concentrations of the synthetic M2e peptide as described in Materials and methods. The estimated amount of CMV-M2e was $6-8 \mu \mathrm{g} / \mathrm{g}$ of leaf tissue (or $\sim 0.1 \%$ of total soluble protein).

\section{Bacterial expression of $C M V C P$-M2e recombinant protein}

Following expression in $E$. coli, recombinant proteins were found to accumulate in inclusion bodies. Interestingly, aggregates of protein in inclusion bodies, which were not yet treated with denaturing $8 \mathrm{M}$ urea buffer, were immunoreactive with both CMV and M2e antibodies (not shown). When solubilized inclusion bodies were purified on high affinity Ni-NTA spin columns and electrophoresed through 10-20\% Tris-Glycine gels, two single bands, corresponding to near homogeneous proteins (from constructs pET151/CMV CP-WT and pET151/ CMV CP-M2e, respectively) fused to the expression vector's elements (polyhistidine region, V5 epitope and TEV recognition site), were present on both SimplyBlue reagent-stained gels and membranes probed with protein-specific antibodies (Fig. 3). Concentration of recombinant CMV CP-M2e protein, affinity-purified from a small-scale $5 \mathrm{ml}$ culture was as high as $\sim 118 \mu \mathrm{g} / \mathrm{ml}$, as determined by Bradford assay.

\section{Discussion}

This study is a continuation of our work on the PVX/ CMV CP expression system. We demonstrated previously that coat protein of CMV-Ix expressed from heterologous PVX virus is capable of forming stable virus-like particles (VLP) that can accommodate incorporation of useful foreign epitopes into surface-displayed $\beta \mathrm{H}-\beta \mathrm{I}$ loop (motif 5) [9]. Here we provide evidence that the CMV capsid can be used for expression in plants of the external domain of avian influenza A virus M2 protein. VLP-displayed M2e epitope remained immunoreactive, which was demonstrated by its binding to the epitope-specific antibody. Whole leaf squash blot analysis of plants infected with recombinant PVX/CMV CP-M2e virus showed that CMV CP-M2e antigen was distributed throughout the entire infected leaf tissue and thus accumulates in plants systemically as does the virus itself.

In addition to transient expression in plants, $6 \times$ his-tagged CMV CP-M2e was efficiently expressed in E. coli and recognized by both CMV- and M2e-specific antibodies.

VLPs are increasingly used as both vaccine candidates against parental viruses and as stabilizers and adjuvants for inserted foreign antigens to enhance broad immune response to fused epitopes. Recent outbreaks of HPAIV, highly pathogenic avian influenza virus subtype H5N1 that normally occurs in domestic fowl but was also found in migratory birds, different mammals and humans, created a real threat of pandemic and an urgent need to develop a vaccine strategy fundamentally different from existing vaccine routes. The current flu vaccines are based on inactivated or live attenuated (weakened) viruses regularly updated to incorporate antigens derived from major strains in circulation [12]. Plasmid-based reverse-genetics approach that produce infectious viruses from cDNA copies of its genes, is rapidly emerging as an alternative technology to produce any needed viral mutant by genetic reassortment in vitro [13]. The M2 protein is a highly 

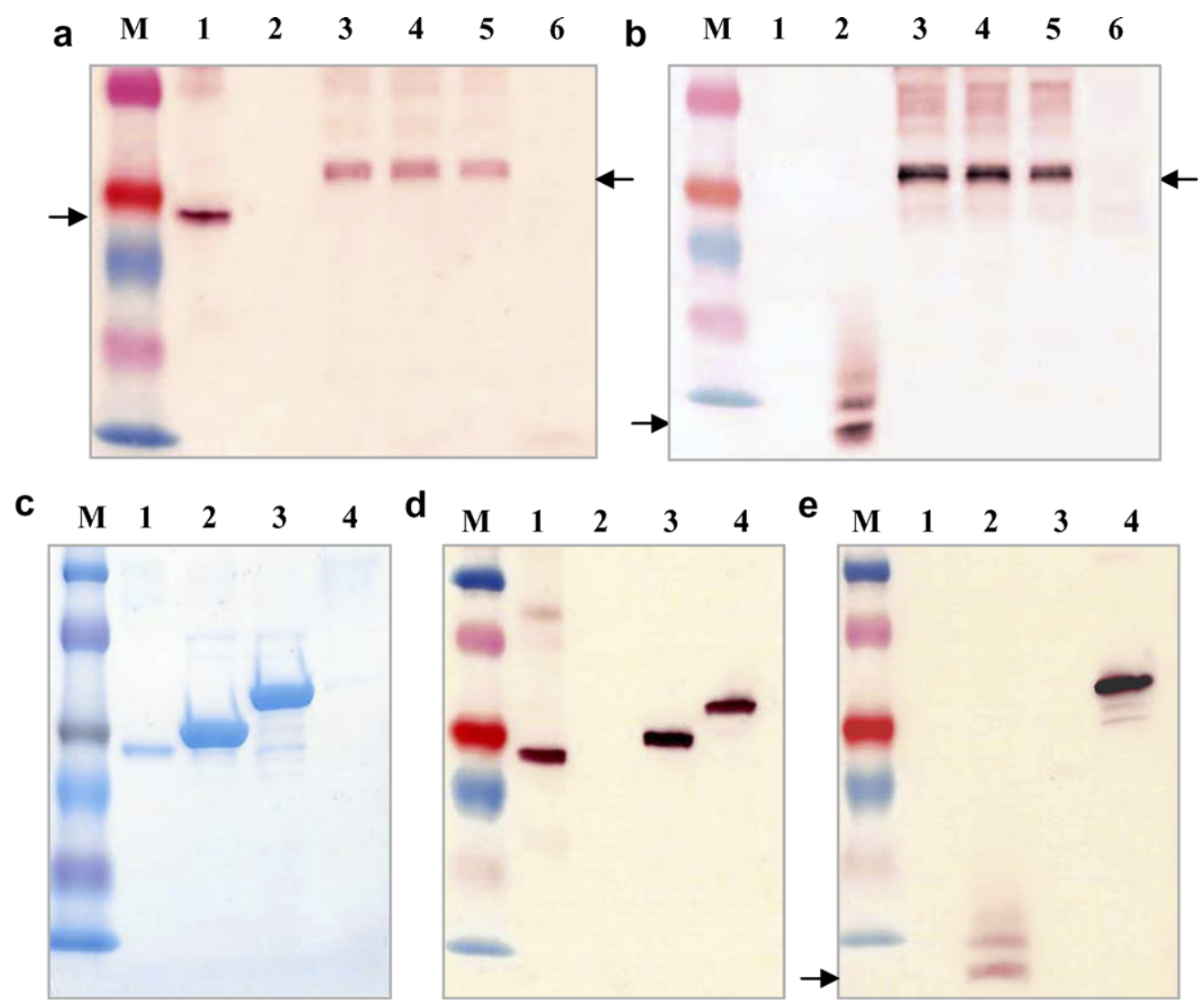

Fig. 3. ( $a$ and b) Western blots of extractions from PVX/CMV CP-M2e plants probed with CMV (a) and M2e (b) antibodies. M, ColorBurst Molecular weights (kDa) protein marker (Sigma): 40, 30, 20, 13, and 8; lane 1, purified preparation of WT CMV Ixora virus; lane 2, M2e synthetic peptide, lanes 3-5, different plants infected with recombinant PVX/CMV CP-M2e virus; lane 6, uninfected control plant. Arrows on the left indicate position of positive controls; arrows on the right indicate positions of expected CMV CP/M2e bands. (c-e) expression of the CMV CP-M2e antigen in bacteria. (c) Gel was stained with SimplyBlue ${ }^{\mathrm{TM}}$ SafeStain (Invitrogen). M, ColorBurst Molecular weights (kDa) protein marker (Sigma), 65, 40, 30, 20, 13, and 8; lane 1, $2 \mu \mathrm{g}$ of purified preparation of WT CMV Ixora virus; lane 2, $10 \mu \mathrm{l}$ of IPTG-induced, 6× His-tagged preparation of CMV CP WT expressed in E. coli and purified using Ni-NTA spin column; lane 3, $10 \mu$ of IPTG-induced, $6 \times$ His-tagged preparation of CMV CP/M2e expressed in E. coli and purified using $\mathrm{Ni}-\mathrm{NTA}$ spin column; lane 4, same as in 3 , uninduced sample. (d and e) Western blots of recombinant proteins expressed in $E$. coli, and probed with CMV antibodies (d) or M2e antibodies (e). M, ColorBurst Molecular weights (kDa) protein marker (Sigma), lane 1, 500 ng of purified preparation of WT CMV Ixora virus; lane 2, $2 \mu \mathrm{g}$ of synthetic M2e peptide; lane 3, IPTG-induced $6 \times$ His-tagged preparation of CMV CP WT expressed in E. coli and purified using Ni-NTA spin column, 1:10 dilution of the sample used for SimplyBlue ${ }^{\mathrm{TM}}$ stained gel, $2 \mu$ loaded; lane 4, IPTG-induced, $6 \times$ His-tagged preparation of CMV CP/M2e protein expressed in E. coli and purified using Ni-NTA spin column, 1:10 dilution of the sample used for SimplyBlue ${ }^{\mathrm{TM}}$ stained gel, $2 \mu \mathrm{l}$ loaded. Arrow indicates position of M2e positive control.

conserved antigen that has remained nearly unchanged over several decades. Although it is weakly immunogenic, its potential as a vaccine candidate is supported by studies showing that the M2e fusion to another protein can elicit protective antibody response and most importantly, by the antigen's stability, which would lessen the burden of yearly updating influenza vaccines to reflect the current circulating strain.

The first study aimed to develop M2-based influenza vaccine used translational fusion to hepatitis B virus core ( $\mathrm{HBc}$ ) antigen as an adjuvant [7]. The antigen was expressed in bacteria and provided $90-100 \%$ protection against a lethal virus challenge. The M2e-based vaccine was further optimized by increasing amounts of M2e copies linked to the N-terminus of the HBc [14]. Preclinical studies of M2e synthetic peptide conjugated with keyhole limpet hemocyanin (KLH) demonstrated protection against lethal challenge of $\mathrm{H} 1 \mathrm{~N} 1$ or $\mathrm{H} 3 \mathrm{~N} 1$ virus in mice [6]. M2e antisera cross-reacted with a wide range of human influenza A strains.

To our knowledge, prior to this study there were no attempts to explore plant systems for the expression of HPAIV antigens. Meanwhile, in planta agricultural scale production of the viral M2e epitope, genetically fused to appropriate carrier molecule to enhance its immunogenicity, would represent a new and unconventional strategy for development of vaccine candidate against the virus. In addition to the expression system described in this work, one of the natural carriers-adjuvants previously tested in plants is non-toxic B subunit of cholera toxin (CTB). Our earlier results on using CTB as a carrier for neutralizing epitope of hepatitis C virus demonstrated that CTB transiently expressed in plants retained its functional activity, formed pentamers and contributed to the immune response 
against fused HCV epitope [15]. Perhaps using CTB as a carrier for M2e, that is four amino acids shorter than Hypervariable Region 1 of $\mathrm{HCV}$, could also result in a stable and effective antigenic module eliciting immune response against viral protein.

Expression in $E$. coli was conducted to assess an antigenicity of the recombinant protein prior to large-scale production in plants, that is, resultant protein will be used for immunization and screening of generated antibodies against the M2e epitope fused to CMV capsid. It was also important to demonstrate applicability of the protein production in both plant and bacterial systems. The CMV CP-M2e protein produced in E. coli BL21 Star (DE3) accumulated in the form of inclusion bodies, which were immunoreactive themselves before solubilization in denaturing buffer and affinity purification of the His-tagged protein. It was reported elsewhere for bacterially expressed antigen of classical swine fever virus (CSFV), that inclusion bodies can induce both systemic and mucosal responses when administered orally and thus be a convenient alternative to other antigen delivery systems as well as to a necessity of mucosal adjuvant [16]. Although it is unknown in what form the conglomerates of CMV CP-M2e protein exist in inclusion bodies, the fact that they are highly immunoreactive could possibly mean that the antigen may well provoke immune response in vivo without any need of further purification from insoluble precursor.

The investigation of new insights and technologies in the field of traditional vaccination against influenza viruses are urgently needed to both reduce the cost of current vaccines and to explore the entirely novel strategies of vaccine development. Plant-derived vaccines raised a great hope of availability of the preparations to developing countries, lower production costs and increased safety standards. This initial study demonstrates the feasibility of expression of an immunogenic epitope of influenza $\mathrm{A}$ virus in plants and the prospects of using a plant-virus based carrier as an alternative to the previously reported M2e conjugate vaccines.

\section{Acknowledgment}

We thank Darya Zharikova for help with preliminary experiments and discussions.

\section{References}

[1] D.O. White, F.J. Fenner, Medical Virology, Academic Press, 1999.

[2] S.A. Plotkin, W.A. Orenstein, Vaccines, fourth ed., Elsevier Inc., 2004.

[3] Center for Disease Control and Prevention, Key facts about avian influenza (Bird Flu) and avian influenza A (H5N1) virus, http:// www.cdc.gov/flu/avian/gen-info/facts.htm (2006).

[4] World Health Organization, Cumulative Number of Confirmed Human Cases of Avian Influenza A/(H5N1) Reported to WHO, http://www.who.int/csr/disease/avian_influenza/country/cases_table_2006_09_25/en/index.html (2006).

[5] R.A. Lamb, S.L. Zebedee, C.D. Richardson, Influenza virus M2 protein is an integral membrane protein expressed on the infected-cell surface, Cell 40 (1985) 627-633.

[6] J. Fan, X. Liang, M.S. Horton, H.C. Perry, M.P. Citron, G.J. Heidecker, T.M. Fu, J. Joyce, C.T. Przysiecki, P.M. Keller, V.M. Garsky, R. Ionescu, Y. Rippeon, L. Shi, M.A. Chastain, J.H. Condra, M.E. Davies, J. Liao, E.A. Emini, J.W. Shiver, Preclinical study of influenza virus A M2 peptide conjugate vaccines in mice, ferrets, and rhesus monkeys, Vaccine 22 (2004) 2993-3003.

[7] S. Neirynck, T. Deroo, X. Saelens, P. Vanlandschoot, W.M. Jou, W. Fiers, A universal influenza A vaccine based on the extracellular domain of the M2 protein, Nat. Med. 10 (1999) 1157-1163.

[8] M. De Filette, W. Fiers, W. Martens, A. Birkett, A. Ramne, B. Lowenadler, N. Lycke, W.M. Jou, X. Saelens, Improved design and intranasal delivery of an M2e-based human influenza A vaccine, Vaccine 24 (2006) 6597-6601.

[9] A. Natilla, R.W. Hammond, L.G. Nemchinov, Epitope presentation system based on cucumber mosaic virus coat protein expressed from a potato virus X-based vector, Arch. Virol. 151 (2006) 1373-1386.

[10] S. Hendy, Z.C. Chen, H. Barker, S. Santa Cruz, S. Chapman, L. Torrance, W. Cockburn, G.C. Whitelam, Rapid production of singlechain $\mathrm{Fv}$ fragments in plants using a potato virus $\mathrm{X}$ episomal vector, J. Immunol. Methods 231 (1999) 137-146.

[11] X. He, S. Liu, K. Perry, Identification of epitopes in cucumber mosaic virus using a phage-displayed random peptide library, J. Gen. Virol. 79 (1998) 3145-3153.

[12] Center for Disease Control and Prevention, 2006-07 Influenza Vaccine Composition, http://www.cdc.gov/flu/professionals/vaccination/composition0607.htm (2006).

[13] T. Horimoto, Y. Kawaoka, Strategies for developing vaccines against H5N1 influenza A viruses, Trends Mol. Med. 12 (2006) 506-514.

[14] M. De Filette, W. Min Jou, A. Birkett, K. Lyons, B. Schultz, A. Tonkyro, S. Resch, W. Fiers, Universal influenza A vaccine: optimization of M2-based constructs, Virology 337 (2005) 149-161.

[15] L.G. Nemchinov, T.J. Liang, M.M. Rifaat, H.M. Mazyad, A. Hadidi, J.M. Keith, Development of a plant-derived subunit vaccine against hepatitis C virus, Arch. Virol. 145 (2000) 2557-2573.

[16] M. Kesik, V. Saczynska, B. Szewczyk, A. Płucienniczak, Inclusion bodies from recombinant bacteria as a novel system for delivery of vaccine antigen by the oral route, Immunol. Lett. 91 (2004) 197-204. 